\title{
Fermentation performance and physiology of two strains of Saccharomyces cerevisiae during growth in high gravity spruce hydrolysate and spent sulphite liquor
}

\author{
Emma Johansson ${ }^{1,2^{*}}$, Charilaos Xiros ${ }^{1}$ and Christer Larsson ${ }^{1 *}$
}

\begin{abstract}
Background: Lignocellulosic materials are a diverse group of substrates that are generally scarce in nutrients, which compromises the tolerance and fermentation performance of the fermenting organism. The problem is exacerbated by harsh pre-treatment, which introduces sugars and substances inhibitory to yeast metabolism. This study compares the fermentation behaviours of two yeast strains using different types of lignocellulosic substrates; high gravity dilute acid spruce hydrolysate (SH) and spent sulphite liquor (SSL), in the absence and presence of yeast extract. To this end, the fermentation performance, energy status and fermentation capacity of the strains were measured under different growth conditions.
\end{abstract}

Results: Nutrient supplementation with yeast extract increased sugar uptake, cell growth and ethanol production in all tested fermentation conditions, but had little or no effect on the energy status, irrespective of media. Nutrient-supplemented medium enhanced the fermentation capacity of harvested cells, indicating that cell viability and reusability was increased by nutrient addition.

Conclusions: Although both substrates belong to the lignocellulosic spruce hydrolysates, their differences offer specific challenges and the overall yields and productivities largely depend on choice of fermenting strain.

Keywords: Lignocellulosic material, Nutrients, Energy charge, Fermentation capacity, High gravity fermentation

\section{Background}

Lignocelluloses are a diverse group of substrates [1] including cellulose, hemicellulose, lignin and extractives [2], which produce inhibitors during hydrolysis. The quantity of inhibitor depends not only on the origin of the material but also on the pre-treatment and hydrolysis method. Fermentation inhibitors, which inhibit yeast metabolism, include 5-hydroxymethyl furfural (HMF), 2-furaldehyde (furfural), phenolic compounds and weak acids for review, see [3-6]. Reportedly, weak acids exert a growth inhibitory effect by inflow of non-dissociated acid into the cytoplasm of the microorganism [7]. HMF and furfural are consumed by S. cerevisiae, with consequent cost of ATP $[8,5]$.

\footnotetext{
* Correspondence: emma.johansson@processum.se; christer.larsson@ chalmers.se

'Department of Chemical and Biological Engineering, Chalmers University of Technology, 41296 Göteborg, Sweden

${ }^{2} \mathrm{SP}$ Processum AB, 89122 Örnsköldsvik, Sweden
}

The inhibitory effect of phenolic compounds on yeast metabolism remains under investigation. A feasible suggestion is that phenolic compounds degrade the cell membrane integrity, reducing the membrane's efficacy as a selective barrier [9]. To release high amounts of monosaccharides for fermentation, lignocelluloses (on account of their recalcitrant nature) often require harsh pre-treatment conditions. In most cases, the quantity of inhibitors increases with the severity of pre-treatment. Therefore, scientists seek mild pre-treatments that maximize the saccharification yields.

Besides containing growth inhibitors, lignocelluloses are generally scarce in nutrients and nutrient supplementation is thought to increase fermentation performance [10-12]. Earlier studies on such raw materials have identified lack of nitrogen as a crucial limiting factor in fermentations. Nitrogen is especially important for fermentative perform- 
ance because it promotes cell proliferation [13,14] and thereby ethanol yields, since the ethanol production rate is maximized in actively growing cells $[15,16]$.

Efficient distillation energy requires both high productivity and high ethanol titres. A prerequisite of ethanol production is high-gravity substrate, which theoretically yields at least $40-50 \mathrm{~g} \mathrm{~L}^{-1}$ ethanol [17]. In practice, however, increasing the initial high dry matter content will also increase the concentrations of inhibitory compounds. The tolerance to inhibitors and the fermentation performance of cells depends on the nature of the substrate and the extent to which the fermenting organism is adapted to the specific challenges imposed by the substrate $[18,19]$. Substrate stress affects the energy metabolism of the yeast cells, since many stress responsive processes depend on ATP availability [20]. Some of the inhibitory compounds in lignocellulosic material appear to decrease the specific sugar uptake rate and the specific ethanol production rate $[21,5]$, both of which are highly correlated with ATP production. Adenine nucleotides also participate in numerous intracellular reactions, and their intracellular concentrations may greatly affect metabolism and yeast cell performance [22]. The study of energy metabolism can therefore provide insights into the maintenance requirements of yeast cells in lignocellulosic fermentations.

To determine the re-usability of the yeast cells, we must know whether the cells can sustain high ethanol production rates under extended periods of stress and nutrient limitation. This is crucial for processes involving cell recycling or re-circulation. During cultivation, the ethanol production rate may not reflect the ethanol production capacity, because cell performance is reduced by the abovementioned substrate limitations. In this study, we measured the fermentation capacity of the cells after re-inoculation in a non-inhibitory nutritionally rich medium. Using this approach, we can detect whether the cells are irreversibly affected by the previous fermentation conditions.

To evaluate the different performance of yeast strains grown in different lignocellulosic substrates and the effect of nutrient addition, the fermentation performance, energy status and fermentative capacity of the strains were measured.

\section{Methods}

\section{Microorganisms}

Two yeast strains were used: Saccharomyces cerevisiae Thermosacc (Thermosacc) (Lallemand, USA) and Saccharomyces cerevisiae CCUG 53310 (CCUG) (Culture Collection University of Gothenburg, Sweden). Thermosacc is a commercial thermotolerant strain of S. cerevisiae developed to withstand the stress of industrial fermentation and higher concentrations of organic acids [23]. CCUG is an industrially harvested yeast strain, selected because it originates from spent sulphite liquor ethanol plant.

\section{Media and chemicals}

The fermentation media were a filtrated spruce dilute-acid hydrolysate $(\mathrm{SH})$ with a water-insoluble solids (WIS) content of 20\% (kindly provided by SEKAB E-Technology) and spent sulphite liquor (SSL) (kindly provided by Domsjö Fabriker, Aditya Birla). The concentrations of available hexoses, weak acids, HMF, furfural and phenolics in the spruce hydrolysate were $66.3 \mathrm{~g} \mathrm{~L}^{-1}, 8.0 \mathrm{~g} \mathrm{~L}^{-1}, 2.4 \mathrm{~g} \mathrm{~L}^{-1}$, $1.9 \mathrm{~g} \mathrm{~L}^{-1}$ and $5.0 \mathrm{~g} \mathrm{~L}^{-1}$ respectively. In the spent sulphite liquor, the respective concentrations of the same compounds were $35.6 \mathrm{~g} \mathrm{~L}^{-1}, 6.4 \mathrm{~g} \mathrm{~L}^{-1}, 0.3 \mathrm{~g} \mathrm{~L}^{-1}, 0.2 \mathrm{~g} \mathrm{~L}^{-1}$ and $1.0 \mathrm{~g} \mathrm{~L}^{-1}$. The spruce hydrolysate slurry was centrifuged and the supernatant was filtered through $0.2 \mu \mathrm{m}$ pore size filters. The spent sulphite liquor was used without centrifugation and filtration. All chemicals were of analytical grade and were purchased from Sigma Aldrich (Sweden). Yeast extract was purchased from Becton Dickinson (Sweden).

\section{Cell cultivations and fermentations}

Cells were proliferated under aerobic conditions in $250 \mathrm{ml}$ Erlenmeyer flasks using a defined media containing excess nutrients and vitamins [7]. The flasks were incubated at $30^{\circ} \mathrm{C}$ in an orbital shaker at $180 \mathrm{rpm}$. At the end of the aerobic growth phase (when the glucose was consumed) $\mathrm{SH}$ or SSL was added to the culture to a final concentration of $25 \%$ of the initial concentration (final volume ratio in the culture 1:4). The cultures were again aerobically incubated until all glucose was consumed. The fermentations were performed in batch mode in $300 \mathrm{ml}$ Erlenmeyer flasks equipped with a glycerol loop to release $\mathrm{CO}_{2}$ and exclude oxygen. The temperature was set to $30^{\circ} \mathrm{C}$ and agitation to $150 \mathrm{rpm}$. Prior to inoculation and filtration, the $\mathrm{pH}$ of all cultivations was adjusted to 5.5 with $5 \mathrm{M} \mathrm{NaOH}$. As nutrient supplement, $1 \%(\mathrm{w} / \mathrm{v})$ yeast extract was supplied according to the experimental design.

All experiments were performed in duplicate. CCUG is a flocculating strain, which affects the reproducibility of its results [24].

\section{Fermentation capacity tests}

In the fermentation capacity tests, a $10 \mathrm{ml}$ sample was withdrawn from the lignocellulosic fermentation, and the cells were pelleted by centrifugation (SIGMA Laborzentrifugen $\mathrm{GmbH}$, Osterode, Germany) at $4^{\circ} \mathrm{C}$. The pelleted cells were inoculated in a nutritionally rich media containing $20 \mathrm{~g} \mathrm{~L}^{-1}$ glucose, $20 \mathrm{~g} \mathrm{~L}^{-1}$ peptone and $10 \mathrm{~g} \mathrm{~L}^{-1}$ yeast extract. Throughout the next $60 \mathrm{~min}$, samples were regularly withdrawn $(t=10,20,40$ and $60 \mathrm{~min})$ and their ethanol content determined. 


\section{Cell viability test}

Cell viability was evaluated by enumerating the colony forming units (CFU). Cells were grown on nutritionally rich non-inhibitory agar plates containing $20 \mathrm{~g} \mathrm{~L}^{-1}$ glucose, $20 \mathrm{~g} \mathrm{~L}^{-1}$ peptone and $10 \mathrm{~g} \mathrm{~L}^{-1}$ yeast extract.

\section{Extraction of ATP, ADP, AMP and measurements of energy status}

Samples $(3 \mathrm{ml})$ were taken for ATP, ADP and AMP measurements and quenched as described in [25] in $17 \mathrm{ml}$ pure methanol maintained at $-40^{\circ} \mathrm{C}$. The cells were pelleted in a centrifuge (SIGMA Laborzentrifugen $\mathrm{GmbH}$, Osterode, Germany) at $-20^{\circ} \mathrm{C}, 4000 \mathrm{~g}$ for $5 \mathrm{~min}$, flash-frozen in liquid nitrogen and stored at $-80^{\circ} \mathrm{C}$ until analysis. The ATP, ADP and AMP were then extracted according to [26]: $0.5 \mathrm{ml}$ of $0.51 \mathrm{M}$ trichloroacetic acid (TCA) containing $17 \mathrm{mM}$ EDTA was added and the samples were incubated at $4^{\circ} \mathrm{C}$ for 15 minutes. The extracts were then centrifuged at $18078 \mathrm{~g}$ for $3 \mathrm{~min}$ and subsequently neutralized with $2 \mathrm{M}$ Tris-base.

The energy charge was calculated as follows [27]:

$$
\mathrm{EC}=\left([\mathrm{ATP}]+\frac{1}{2}[\mathrm{ADP}]\right) /([\mathrm{ATP}]+[\mathrm{ADP}]+[\mathrm{AMP}])
$$

\section{Analytical procedures}

The media were analysed by MoRe research using an Aminex HPX-87H column maintained at $45^{\circ} \mathrm{C}$. Glycerol, ethanol and organic acids were detected by an RI detector, and a UV detector was used for HMF and furfural. The eluent was $10 \mathrm{mM} \mathrm{H}_{2} \mathrm{SO}_{4}$ and flow rate was $0.8 \mathrm{ml} \mathrm{min}^{-1}$.

After the fermentation, ethanol and glycerol were analysed by HPLC using an RI detector and an Aminex HPX-87H column with a $30 \mathrm{~mm} \times 4.6 \mathrm{~mm}$ Cation-H BioRad micro-guard column maintained at $45^{\circ} \mathrm{C}$. The eluent was $5 \mathrm{mM} \mathrm{H}_{2} \mathrm{SO}_{4}$ and flow rate was $0.6 \mathrm{ml} \mathrm{min}^{-1}$. Hexoses were analysed by high performance anion exchange chromatography using an electrochemical detector and a $4 \mathrm{~mm} \times 250 \mathrm{~mm}$ Dionex CarboPac PA1 column with a $4 \mathrm{~mm} \times 50 \mathrm{~mm}$ guard column maintained at $30^{\circ} \mathrm{C}$. Elution was performed at $1 \mathrm{ml} \mathrm{min}^{-1}$ using eluents A (300 mM NaOH) and B (100 mM $\mathrm{NaOH}+85 \mathrm{mM}$ sodium acetate). The adenine nucleotides were analysed by HPLC (Ultimate 3000, Dionex Corp., Sunnyvale, US) with an Luna ${ }^{\oplus} 5$ u C18(2) $100 \AA$ LC column (150 $\mathrm{mm} \times 4.6 \mathrm{~mm})$ (Phenomenex Inc., Torrance, US) maintained at $20^{\circ} \mathrm{C}$. The mobile phase was acetonitrile and tetrabutylammonium buffer $(0.005 \mathrm{M}$ tetrabutylammonium hydrogensulfate, $0.01 \mathrm{M} \mathrm{Na}_{2} \mathrm{HPO}_{4}$ ), $\mathrm{pH}$ 7.0. The acetonitrile gradient was as follows: t0 min $6 \%$, t3 min 6\%, t16 min 25\%, t22 min 25\%, t27 min 6\%. The system was then equilibrated for 8 minutes to the initial conditions. The flow rate was $1 \mathrm{ml} / \mathrm{min}$. All detections were performed with a photodiode array detector PDA3000 (Dionex Corp., Sunnyvale, US) operated at $260 \mathrm{~nm}$. Peak identities were confirmed by co-elution with standards and quantified by comparison with standard solutions of known concentrations.

\section{Results and discussion}

This study investigated the effects of fermenting strain, fermentation substrate and nutrient supplementation of the medium on the fermentative performance and physiological characteristics of S. cerevisiae. Effects were evaluated by ethanol production, cell growth, colony forming units, energy status, and fermentation capacity.

\section{Importance of strain selection on the fermentation of lignocellulosic hydrolysates}

Fermenting lignocellulosic hydrolysates and side streams into ethanol or other bulk chemicals is a demanding task for fermenting microorganisms. S. cerevisiae is considered the most robust microorganism for industrial scale fermentation in inhibitory media [28]. However, the fermentation performance of different $S$. cerevisiae strains critically depends on the culturing conditions [29-32]. In selecting an appropriate strain, we should consider the metabolic and physiological characteristics of the strain under the processing conditions ( $\mathrm{T}$ and $\mathrm{pH}$ ), and with regard to the ethanol, sugar and inhibitor concentrations in the fermentation medium. The two C6 fermenting strains of $S$. cerevisiae evaluated in the present study, namely, Thermosacc and CCUG, represent different strain selection strategies. Thermosacc is specifically designed to cope with certain challenges during fermentation, while CCUG has naturally evolved under the harsh industrial conditions prevailing in a sulphite mill.

As shown in Figure 1A, Thermosacc satisfactorily fermented $\mathrm{SH}$ and SSL under the prevailing conditions. After $22 \mathrm{~h}$ fermentation, the ethanol concentrations in $\mathrm{SH}$ - and SSL-containing media were $17 \mathrm{~g} \mathrm{~L}^{-1}$ and $9 \mathrm{~g} \mathrm{~L}^{-1}$, respectively, corresponding to yields of $0.26 \mathrm{~g}_{\text {ethanol }}$ and

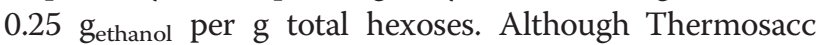
growth was limited in terms of cell dry weight (CDW) (data not shown), the viability of the cells (measured by the CFU, Figure 1) was high and remained more or less stable throughout the fermentation period. The strain harvested from the sulphite mill (CCUG) failed to ferment $\mathrm{SH}$, but performed quite well in SSL, achieving an ethanol concentration of $11 \mathrm{~g} \mathrm{~L}^{-1}$ (a yield of $0.31 \mathrm{~g}_{\text {ethanol }} \mathrm{g}^{-1}$ total available hexoses) after $22 \mathrm{~h}$ fermentation. These results suggest that the CCUG strain has successfully adapted in the sulphite mill, but loses its adaptive benefits when exposed to a moderately different set of conditions. This hypothesis is consistent with earlier reports that stressed cells continuously and randomly produce genetic variants, which are immortalized as mutations only if they permit 

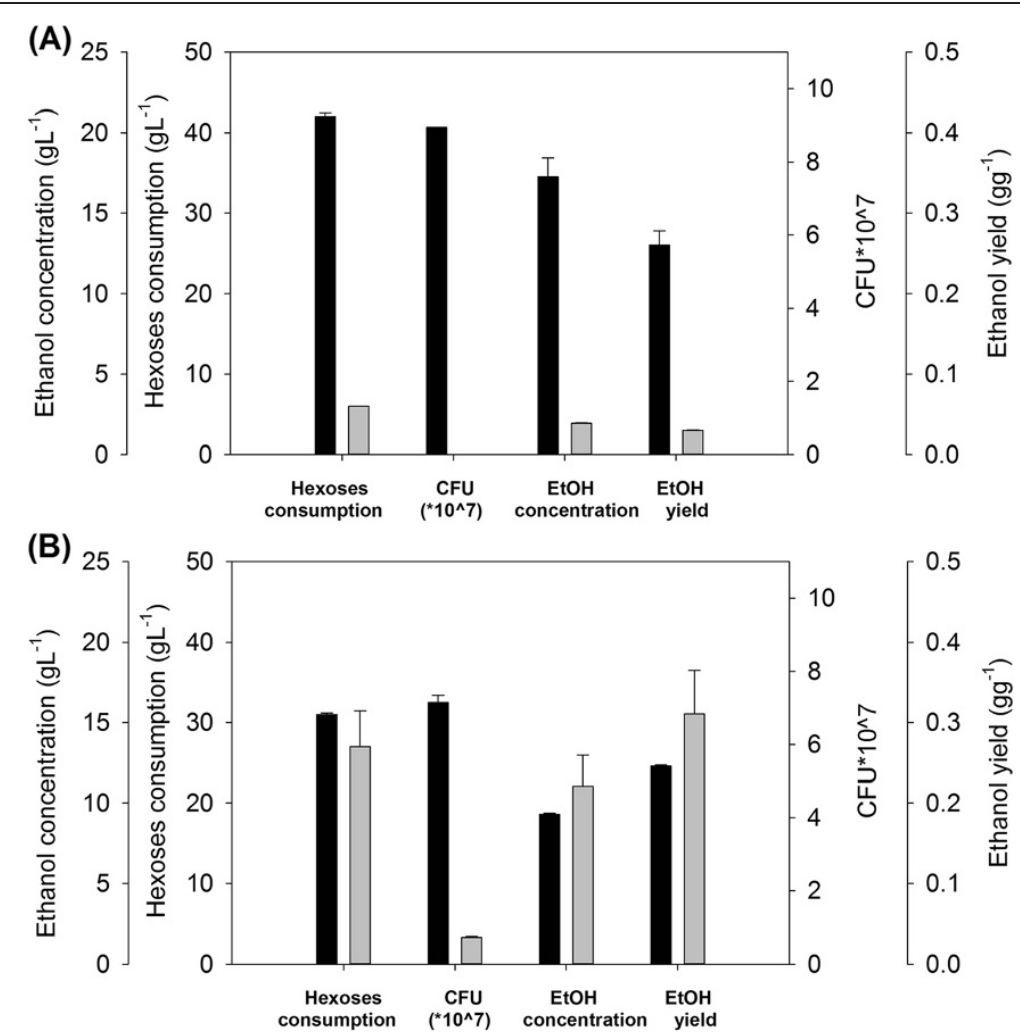

Figure 1 Hexose consumption, viability and ethanol production after $22 \mathrm{~h}$ fermentation. Fermentation substrate was (A) spruce hydrolysate (B) spent sulphite liquor. Black and grey bars denote the S. cerevisiae strains Thermosacc and CCUG, respectively. Error bars indicate the maxima and minima of two independent fermentations.

cell growth [33,34]. The low level of viable cells after $22 \mathrm{~h}$ fermentation in SH indicates that CCUG could not overcome the high toxicity of this foreign medium (Figure 1). However, it should be mentioned that viable cell counts of CCUG were comparably low in SSL, despite the strong fermentation performance in this medium.

\section{Yeast performance in SH and SSL supplemented with yeast extract}

The fermentation performance of yeast is varied by the complexity and variety of substances comprising lignocellulosic materials. The $\mathrm{SH}$ used in the present study is a high gravity substrate with $20 \%$ WIS content. The production of this hydrolysate also increases the concentration of inhibitory compounds and increases the stress factors affecting yeast performance, including osmolarity [35], sugar concentration [36] and ethanol concentration [37]. The concentrations of inhibitors such as acids, HMF, furfural and phenolics are elevated in $\mathrm{SH}$ while sulphite levels are higher in SSL (see Methods).

Supplementation with yeast extract (YE) significantly improved the fermentative performance of both yeast strains. Supplemented Thermosacc produced $25.4 \mathrm{~g} \mathrm{~L}^{-1}$ and $10.3 \mathrm{~g} \mathrm{~L}^{-1}$ ethanol from SH and SSL, respectively, corresponding to yields of $0.38 \mathrm{~g} \mathrm{~g}^{-1}$ hexoses and $0.27 \mathrm{~g} \mathrm{~g}^{-1}$ hexoses (based on total fermentable sugar contents in the media). The effect of yeast extract on $\mathrm{SH}$ fermentation by CCUG was even more impressive. The sugar uptake was doubled, while the ethanol production almost tripled (Figure 2A). As shown in Figure 2, YE addition affected all of the measured fermentation characteristics to similar extent. Increased ethanol production is partially attributable to the increased cell viability in the presence of yeast extract. However, in the CCUG strain, the higher conversion of hexoses into ethanol indicates that $\mathrm{YE}$ additive improved both cell viability and cell metabolism. These findings confirm earlier reports that yeast extract provides cellular building blocks such as amino acids, and also enhances the physiological status of the cells $[38,39]$.

Yeast extract considerably enhanced the biomass formation and viability of Thermosacc in SH-containing medium. The biomass concentration of this organism reached $6 \mathrm{~g} \mathrm{~L}^{-1} \mathrm{CDW}$ (data not shown) and the CFU count was $4.73 \times 10^{7}$ (Figure 2A). Nutrient addition also exerted a positive effect in SSL, although to lesser extent than in SH (Figure 2B). The different effects of nutrient addition to the two media probably reflect the higher maintenance requirement of cells fermenting $\mathrm{SH}$. SH contains higher amounts of inhibitory compounds such as phenolics than SSL $\left(5 \mathrm{~g} \mathrm{~L}^{-1}\right.$ in $\mathrm{SH}$ versus $1 \mathrm{~g} \mathrm{~L}^{-1}$ in SSL). The 


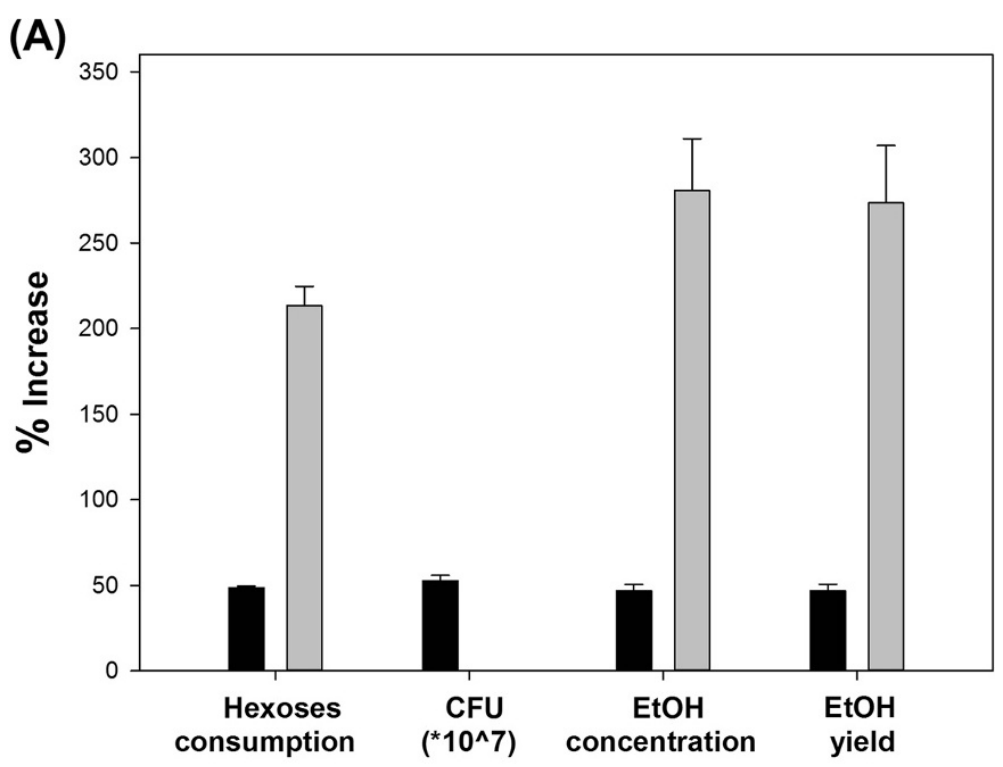

(B)

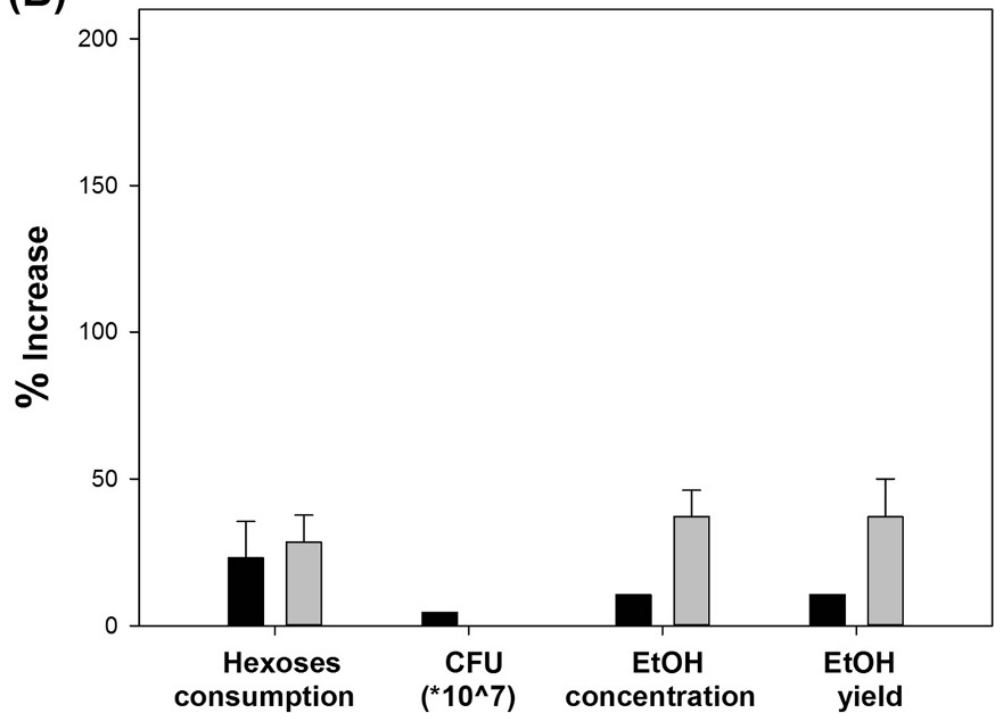

Figure 2 Increased fermentation performance in media supplemented with yeast extract. Black and grey bars indicate fermentations with S. cerevisiae strains Thermosacc and CCUG 53310, respectively. Fermentation substrate is (A) spruce hydrolysate (B) spent sulphite liquor. Error bars indicate the maxima and minima of two independent fermentations.

biomass production of CCUG was similar in both substrates. In this strain, yeast extract addition exerted a strong stimulatory effect despite the low cell viability. In all cases, the decreased concentrations of residual sugars and increased ethanol formation accompanied a higher biomass concentration, reflecting the improved physiological status of the cells.

The positive impact of supplementing lignocellulosic fermentations with yeast extract is most likely attributable to the complex mixture of vitamins, minerals and free amino nitrogens (FAN) present in yeast extract. All of these compounds are necessary for cell growth, which is correlated with ethanol production [15,16]. Ethanol production may be additionally enhanced by free amino nitrogens, whose potential role in the redox balance may lower the need for glycerol production [13].

Energy status of yeast cells cultivated in SH and SSL in the absence and presence of yeast extract

Living cells acquire energy through ATP. Besides satisfying a cell's maintenance energy requirements, ATP is required for growth and biomass formation. Under adverse conditions, maintenance energy requirements escalate to the extent that growth becomes ATP-limited [40]. 
Table 1 ATP, ADP and AMP concentrations throughout $24 \mathrm{~h}$ fermentation

\begin{tabular}{|c|c|c|c|c|c|c|c|c|c|c|}
\hline Strain/condition & & ATP & & & ADP & & & AMP & & Energy charge \\
\hline Fermentation time (h) & 0 & 4 & 22 & 0 & 4 & 22 & 0 & 4 & 22 & 22 \\
\hline Thermosacc/SH & $8.06 \pm 0.08$ & $8.02 \pm 0.17$ & $7.29 \pm 0.16$ & $0.18 \pm 0.01$ & $0.33 \pm 0.06$ & $0.15 \pm 0.01$ & $0.16 \pm 0.03$ & $0.15 \pm 0.00$ & $0.08 \pm 0.01$ & 0.98 \\
\hline Thermosacc/SH+ & $10.94 \pm 0.43$ & $11.47 \pm 0.04$ & $5.58 \pm 0.45$ & $0.55 \pm 0.03$ & $0.54 \pm 0.01$ & $0.19 \pm 0.02$ & $0.14 \pm 0.03$ & $0.07 \pm 0.03$ & $0.43 \pm 0.09$ & 0.92 \\
\hline Thermosacc/SSL & $8.83 \pm 0.25$ & $5.39 \pm 0.38$ & $1.48 \pm 0.17$ & $4.76 \pm 0.17$ & $2.85 \pm 0.55$ & $1.10 \pm 0.10$ & $0.23 \pm 0.05$ & $0.21 \pm 0.02$ & $0.14 \pm 0.00$ & 0.75 \\
\hline Thermosacc/SSL+ & $12.86 \pm 0.38$ & $7.01 \pm 0.92$ & $1.75 \pm 0.63$ & $9.77 \pm 0.08$ & $6.40 \pm 0.49$ & $2.13 \pm 0.57$ & $0.14 \pm 0.03$ & $0.39 \pm 0.07$ & $0.38 \pm 0.05$ & 0.66 \\
\hline CCUG 53310/SH & $7.28 \pm 0.41$ & $3.46 \pm 0.63$ & $2.11 \pm 0.05$ & $3.10 \pm 0.67$ & $2.4 \pm 0.08$ & $1.62 \pm 0.19$ & $3.21 \pm 0.02$ & $2.83 \pm 0.06$ & $2.17 \pm 0.20$ & 0.49 \\
\hline CCUG 53310/SH+ & $13.47 \pm 0.24$ & $5.64 \pm 1.39$ & $2.15 \pm 0.03$ & $6.73 \pm 0.06$ & $3.53 \pm 0.54$ & $1.67 \pm 0.14$ & $0.33 \pm 0.01$ & $4.99 \pm 0.48$ & $2.68 \pm 0.29$ & 0.46 \\
\hline CCUG 53310/SSL & $4.95 \pm 3.54$ & N.D. & $7.42 \pm 6.61$ & $3.40 \pm 1.79$ & N.D. & $3.16 \pm 2.13$ & $0.05 \pm 0.05$ & N.D. & $0.08 \pm 0.02$ & 0.84 \\
\hline CCUG 53310/SSL+ & $5.77 \pm 3.11$ & $5.01 \pm 0.42$ & $6.26 \pm 1.49$ & $5.23 \pm 1.65$ & $3.46 \pm 0.15$ & $5.07 \pm 1.81$ & $0.08 \pm 0.01$ & $0.29 \pm 0.10$ & $1.59 \pm 0.73$ & 0.68 \\
\hline
\end{tabular}

Concentrations are expressed in $\mu \mathrm{mol}(\mathrm{g} \mathrm{DW})^{-1}$ unless otherwise stated. SH $=$ Spruce hydrolysate. SSL $=$ Spent sulphite liquor. + indicates that the fermentation has been supplemented with yeast extract. \pm indicates the maximum and minimum of two independent fermentations. 
Concomitant with ATP reduction, AMP levels elevate, with potential decrease in energy charge. Nutrient-poor lignocellulosic substrates contain a cocktail of growth inhibiting substances (reviewed in [3]) that encourage such phenomena. From an ethanol production perspective, low ATP levels are not necessarily disadvantageous, since biomass formation can be restrained while glycolysis and ethanol flux is stimulated [41]. However, ATP levels must remain above a certain threshold to prevent glycolysis inhibition [42].
Cultivated in $\mathrm{SH}$, the Thermosacc strain retained high ATP levels and low AMP levels (Table 1). In contrast, ATP levels temporally declined in the CCUG strain, while AMP accumulated. In SSL-cultivated Thermosacc, ATP levels dramatically decreased after 22 hours fermentation, while AMP levels did not appreciably increase. Again, CCUG was relatively resistant to SSL and retained its ATP levels after 22 hours fermentation (Table 1). These results are consistent with the fermentative performance of the two strains.

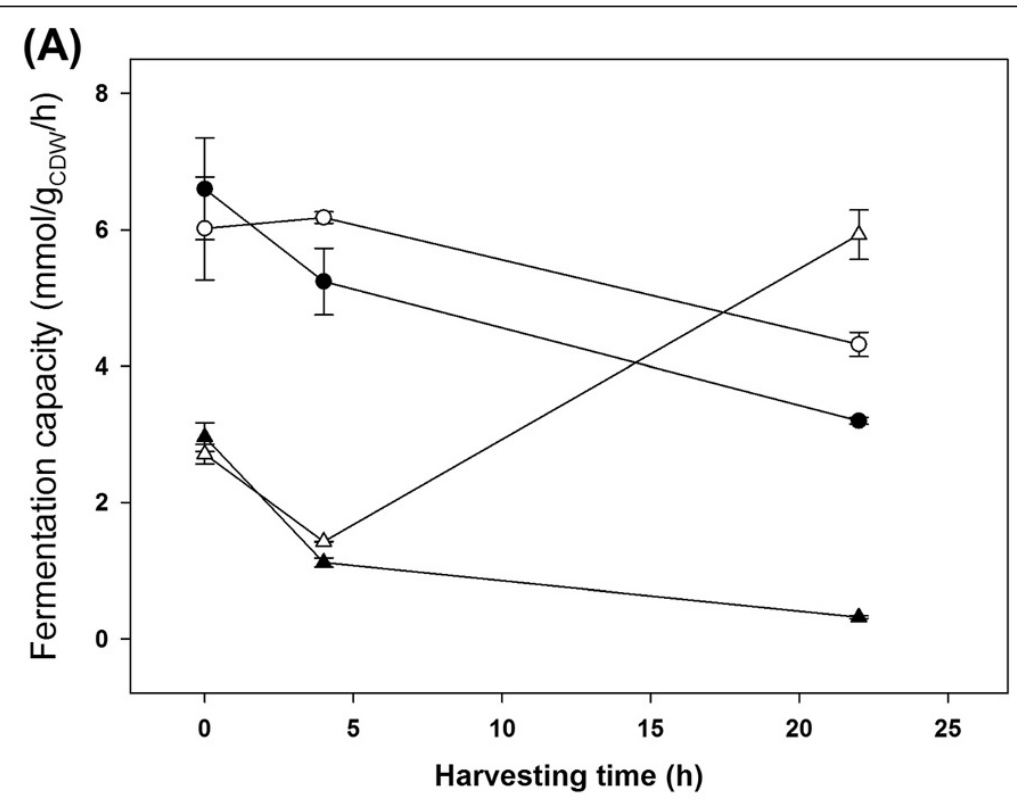

(B)

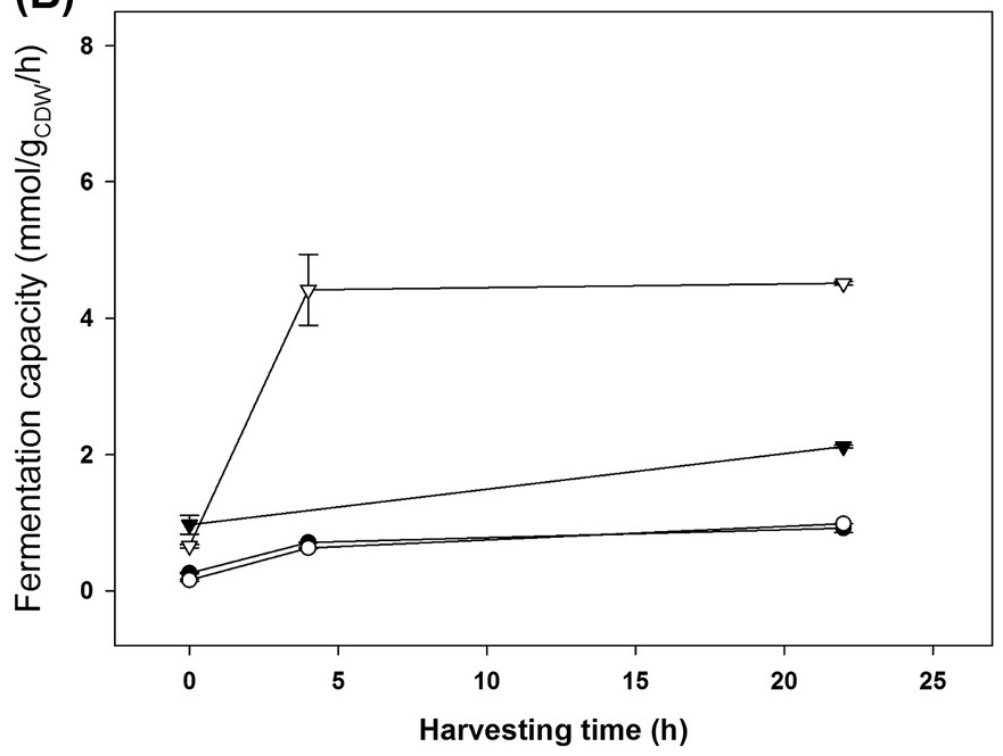

Figure 3 Fermentation capacity following re-inoculation in YPD media. Open and closed symbols represent cells harvested from nutrientsupplemented and non-supplemented fermentations, respectively. Circles and triangles denote the S. cerevisiae strains Thermosacc and CCUG 53310, respectively. (A) Fermentation capacity of cells harvested from spruce hydrolysate. (B) Fermentation capacity of cells harvested from spent sulphite liquor. Error bars indicate the maxima and minima of two independent fermentations. 
Nutrient supplementation exerted little effect on energy charge in either medium. Throughout the SH fermentation, the energy charge in Thermosacc and CCUG was approximately 1 and below 0.5 , respectively (Table 1 ). The low energy charge of CCUG reflects the low viability of the population, which may in turn reflect the high maintenance requirements of this strain. However, CCUG exhibited a higher energy charge in SSL medium, again suggesting that this yeast strain is better adapted to SSL and metabolically equipped for the challenges imposed by this substrate. This hypothesis is supported by the much higher titres and ethanol yields obtained by CCUG in SSL than in $\mathrm{SH}$ (Figure 1B). On the other hand, the energy charge of Thermosacc was slightly lower in SSL than in SH (Table 1). This reduction was accompanied by noticeable deterioration in fermentation performance. Hence, under these challenging conditions, maintaining high energetic status is crucial to sustaining a high fermentation rate. However, the absolute ATP levels were not obviously correlated with the rates of glycolysis and ethanol formation.

\section{Changes in fermentation capacity during cultivation in $\mathrm{SH}$ and SSL in the absence and presence of yeast extract}

The fermentation capacity of a cell quantifies the ability of the cell to produce ethanol in non-inhibitory nutrient rich media. This measure indicates whether the reduced ethanol production induced by cultivation in lownutrient lignocellulosic media is restored when the cells are transferred to optimal, non-inhibitory conditions. By investigating how fermentation capacity relates to nutrient supplementation, we can assess whether yeast cells fermenting a lignocellulosic media can be revitalised and consequently reused.

Nutrient supplementation to the $\mathrm{SH}$ fermentation enhanced the fermentation capacity of Thermosacc, although this strain demonstrated reasonable fermentation capacity in the absence of additional nutrients (Figure 3A). The CCUG strain harvested from SH fermentations performed poorly when re-inoculated in non-inhibitory nutritional rich media, supporting the hypothesis that CCUG cannot ferment SH. Conversely, Thermosacc demonstrated very poor fermentation capacity in SSL, irrespective of nutrient addition, whereas CCUG responded very positively to nutrient-supplemented SSL. This suggests that CCUG is less affected by the conditions prevailing in SSL than Thermosacc (Figure 3B). The fermentation capacity of CCUG cells harvested from SSL fermentations also increased over time, although levels were initially low. In contrast, the $\mathrm{SH}$ fermentation capacity of CCUG generally deteriorated over time. Excepting Thermosacc fermenting SSL, the fermentation capacity was improved in cells harvested from nutrient-supplemented fermentations, indicating that cell viability and revitalizing ability is increased in nutrient-supplemented media.

\section{Conclusion}

This study highlights the importance of selecting a fermentation strain that is well adapted to the prevailing process conditions. The yeast strain CCUG, originally isolated from a sulphite mill, demonstrated stronger performance than Thermosacc in SSL media, while the opposite was observed in SH media. Nutrient supplementation did not moderate this difference, but markedly improved the performance of both strains in both substrates.

\section{Competing interests}

The authors declare that they have no competing interests.

\section{Authors' contributions}

EJ participated in the design of the study, carried out the fermentations, analysed the results and partially wrote the manuscript. CX participated in the experimental procedure, the HPLC analysis, result analysis and writing of the manuscript. CL conceived the study and participated in analysing the results and writing the manuscript. All authors read and approved the final manuscript.

\section{Acknowledgments}

Financial support by the Nordic Top-level Research Institute, the county administrative board of Västernorrland, SP Processum and the Kempe Foundation is greatly acknowledged. MoRe research is also acknowledged for performing analysis.

Received: 12 December 2013 Accepted: 24 April 2014

Published: 21 May 2014

\section{References}

1. Jeon YJ, Xun Z, Rogers PL: Comparative evaluations of cellulosic raw materials for second generation bioethanol production. Lett Appl Microbiol 2010, 51:518-524.

2. Sjöström E: Wood chemistry fundamentals and applications. Orlando: Academic Press, INC; 1981.

3. Sluiter JB, Ruiz RO, Scarlata CJ, Sluiter AD, Templeton DW: Compositional analysis of lignocellulosic feedstocks. 1. Review and description of methods. J Agric Food Chem 2010, 58:9043-9053.

4. Palmqvist E, Hahn-Hägerdal B: Fermentation of lignocellulosic hydrolysates II: inhibitors and mechanisms of inhibition. Bioresour Technol 2000, 74:25-33.

5. Almeida JRM, Bertilsson M, Gorwa-Grauslund MF, Gorsich S, Lidén G: Metabolic effects of furaldehydes and impacts on biotechnological processes. Appl Microbiol Biotechnol 2009, 82:625-638.

6. Larsson S, Palmqvist E, Hahn-Hägerdal B, Tengborg C, Stenberg K, Zacchi G, Nilvebrant N-O: The generation of fermentation inhibitors during dilute acid hydrolysis of softwood. Enzyme Microb Technol 1999, 24:151-159.

7. Verduyn C, Postma E, Scheffers WA, Dijken JP: Effect of benzoic acid on metabolic fuxes in yeasts: a continous-culture study on the regulation of respiration and alcoholic fermentation. Yeast 1992, 8:501-517.

8. Jones RP: Biological principles for the effects of ethanol. Enzyme Microb Technol 1989, 11:130-153.

9. Heipieper HJ, Weber FJ, Sikkema J, Kewelo H, de Bont JAM: Mechanism of resistance of whole cells to toxic organic solvents. Trends Biotech 1994, 12:409-415.

10. Johansson E, Brandberg T, Larsson C: Influence of cultivation procedure for Saccharomyces cerevisiae used as pitching agent in industrial spent sulphite liquid fermentations. J Ind Microbiol Biotechnol 2011, 38:1787-1792.

11. Jones AM, Ingledew WM: Fuel alcohol production: appraisal of nitrogenous yeast foods for very high gravity wheat mash fermentation. Process Biochem 1994, 29:483-488.

12. Casey GP, Magnus CA, Ingledew WM: High-gravity brewing: effects of nutrition on yeast composition, fermentative ability, and alcohol production. Appl Environ Microbiol 1984, 48:639-646. 
13. Thomas KC, Ingledew WM: Fuel alcohol production: effects of free amino nitrogen on fermentation of very-high-gravity wheat mashes. Appl Environ Microbiol 1990, 56:2046-2050.

14. Albers E, Larsson C, Lidén G, Niklasson C, Gustafsson L: Influence of the nitrogen source on Saccharomyces cerevisiae anaerobic growth and product formation. Appl Environ Microbiol 1996, 62:3187-3195.

15. Devantier R, Scheithauer B, Granato Villas-Boâs S, Pedersen S, Olsson L: Metabolite profiling for analysis of yeast stress response during very high gravity ethanol fermentations. Biotechnol Bioeng 2005, 90:703-714.

16. Bayrock DP, Ingledew WM: Application of multistage continuous fermentation for production of fuel alcohol by very-high-gravity fermentation technology. J Ind Microbiol Biotechnol 2001, 27:87-93.

17. Galbe M, Sassner P, Wingren A, Zacchi G: Process engineering economics of bioethanol production. In Adv Biochem Eng Biotechnol. Volume 108. Edited by Olsson L. Heidelberg: Springer-Verlag; 2007:303-327.

18. Lau MW, Dale BE, Balan V: Ethanolic fermentation of hydrolysates from ammonia fiber expansion (AFEX) treated corn stover and distillers grain without detoxification and external nutrient supplementation. Biotechnol Bioeng 2008, 99:529-539.

19. Alkasrawi M, Rudolf A, Liden G, Zacchi G: Influence of strain and cultivation procedure on the performance of simultaneous saccharification and fermentation of steam pretreated spruce. Enzyme Microb Techno/ 2006, 38:279-286.

20. Gasch AP: The Environmental Stress Response: A Common Yeast Response to Environmental Stresses. In Yeast Stress Responses. Volume 1. Edited by Hohmann S, Mager P. Heidelberg: Springer-Verlag; 2002:11-70.

21. Sárvári Horváth I, Franzén CJ, Taherzadeh MJ, Niklasson C, Lidén G: Effects of furfural on the respiratory metabolism of Saccharomyces cerevisiae in glucose-limited chemostats. Appl Environ Microbiol 2003, 69:4076-4086.

22. Nielsen J: It is all about metabolic fluxes. J Bacterio/ 2003, 185:7031-7035.

23. Lallemand product sheet Thermosacc Dry. [http://www.lallemandbds. com/wp-content/uploads/2012/12/2013_LBDS_Data-Sheet_ThermosaccDry_10080_Data_Rev.00.01.01.2013.pdf]

24. Purwadi R, Brandberg T, Taherzadeh: A possible industrial solution to ferment lignocellulosic hydrolysates to ethanol: Continuous cultivation with flocculating yeast. Int J Mol Sci 2007, 8:920-932.

25. Canelas AB, Ras C, Pierick A, Dam JC, Heijnen JJ, Gulik WM: Leakage-free rapid quenching technique for yeast metabolomics. Metabolomics 2008, 4:226-239.

26. Lundin A, Thore A: Comparison of methods for extraction of bacterial adenine nucleotides determined by firefly assay. Appl Microbiol 1975, 30:713-721.

27. Atkinson DE: The energy charge of the adenylate pool as a regulatory parameter. Interaction with feedback modifiers. Biochem 1968, 7:4030-4034.

28. Olofsson K, Bertilsson M, Liden G: A short review on SSF - an interesting process option for ethanol production from lignocellulosic feedstocks. Biotechnol Biofuels 2008, 1:7.

29. Meneses FJ, Henschke PA, Jiranek V: A survey of industrial strains of Saccharomyces cerevisiae reveals numerous altered patterns of maltose and sucrose utilisation. J Inst Brew 2002, 108:310-321.

30. Martin C, Jönsson LJ: Comparison of the resistance of industrial and laboratory strains of Saccharomyces and Zygosaccharomyces to lignocellulose-derived fermentation inhibitors. Enzyme Microb Technol 2003, 32:386-395.

31. Modig T, Almeida JRM, Gorwa-Grauslund MF, Lidén G: Variability of the response of Saccharomyces cerevisiae strains to lignocellulose hydrolysate. Biotechnol Bioeng 2008, 100:423-429.

32. Stanley D, Bandara A, Fraser S, Chambers PJ, Stanley GA: The ethanol stress response and ethanol tolerance of Saccharomyces cerevisiae. J Appl Microbiol 2010, 109:13-24.

33. Foster PL: Adaptive mutation - the uses of adversity. Annu Rev Microbiol 1993, 47:467-504.

34. Rosenberg SM: Evolving responsively: adaptive mutation. Nat Rev Genet 2001, 2:645-645.

35. Blomberg A, Adler L: Physiology of osmotolerance in fungi. Adv Microb Physiol 1992, 33:145-212.

36. Erasmus DJ, van der Merwe GK, van Vuuren HJJ: Genome-wide expression analyses: metabolic adaptation of Saccharomyces cerevisiae to high sugar stress. FEMS Yeast Res 2003, 3:375-399.
37. Gray WD: Studies on the alcohol tolerance of yeasts. J Bacteriol 1941, 42:561-574.

38. Alfenore S, Molina-Jouve C, Guillouet SE, Uribelarrea J-L, Goma G, Benbadis L: Improving ethanol production and viability of Saccharomyces cerevisiae by a vitamin feeding strategy during fed-batch process. Appl Microbiol Biotechnol 2002, 60:67-72.

39. Jorgensen $\mathrm{H}$ : Effect of nutrients on fermentation of pretreated wheat straw at very high dry matter content. Appl Biochem Biotechnol 2009, 153:44-57.

40. Gustafsson L, Ölz R, Larsson K, Larsson C, Adler L: Energy balancing calculations as a tool to determine maintenance energy requirements under stress conditions. J Pure Appl Chem 1993, 65:1893-1898.

41. Larsson C, Nilsson A, Blomberg A, Gustafsson L: Glycolytic flux is conditionally correlated with ATP concentration in Saccharomyces cerevisiae: a chemostat study under carbon- or nitrogen-limiting conditions. J Bacteriol 1997, 179:7243-7250.

42. Larsson C, Påhlman I-L, Gustafsson L: The importance of ATP as a regulator of glycolytic flux in Saccharomyces cerevisiae. Yeast 2000, 16:797-809.

doi:10.1186/1472-6750-14-47

Cite this article as: Johansson et al:: Fermentation performance and physiology of two strains of Saccharomyces cerevisiae during growth in high gravity spruce hydrolysate and spent sulphite liquor. BMC Biotechnology 2014 14:47.

\section{Submit your next manuscript to BioMed Central and take full advantage of:}

- Convenient online submission

- Thorough peer review

- No space constraints or color figure charges

- Immediate publication on acceptance

- Inclusion in PubMed, CAS, Scopus and Google Scholar

- Research which is freely available for redistribution

Submit your manuscript at www.biomedcentral.com/submit
C BioMed Central 